\title{
Jemuran Otomatis Menggunakan Sensor LDR, Sensor Hujan Dan Sensor Kelembaban Berbasis Arduino Uno
}

\author{
Yayan Hendrian$^{1}$, Yusuf Pribadi Yudatama², Violetta Surya Pratama \\ Universitas Bina Sarana Informatika \\ 1e-mail: yayan.yhn@bsi.ac.id \\ 2e-mail: yusufpribadi07@gmail.com \\ 3 e-mail: viodrz@gmail.com
}

\begin{tabular}{ccc}
\hline Diterima & Direvisi & Disetujui \\
$08-10-2019$ & $08-12-2019$ & $30-01-2020$ \\
\hline
\end{tabular}

\begin{abstract}
Abstrak-Kondisi perubahan cuaca yang ada di Indonesia tidak menentu, sehingga sulit untuk memprediksikan cuaca cerah dan hujan. Hal ini masih menjadi masalah utama bagi masyarakat yang sedang menjemur pakaian terutama pada kondisi cuaca sedang hujan. Biasanya pakaian yang dijemur sering ditinggalkan berpergian, dengan kondisi cuaca yang seperti ini membuat sebagian orang merasa cemas karena tidak sempat lagi untuk mengangkat jemuran pada kondisi cuaca yang sedang hujan. Ditambah lagi iklim tropis di Indonesia yang seringkali mengalami musim hujan berkepanjangan dan ada beberapa daerah yang memiliki curah hujan tinggi sehingga membuat kita was-was ketika menjemur pakaian di luar rumah. Untuk mengatasi masalah tersebut penulis membuat prototype jemuran otomatis yang menggunakan sensor LDR, sensor hujan, dan sensor kelembaban menggunakan Arduino Uno. Selain sensor tersebut juga terdapat tambahan seperti kipas dan motor DC. Dari hasil pengujian alat yang sudah di buat alat dapat bekerja dengan baik. Alat dapat bekerja ketika sensor akan membaca cuaca disekitar, sensor LDR dan sensor hujan berfungsi untuk medeteksi cuaca di sekitar, sedangkan sensor kelembaban berfungsi untuk medeteksi kondisi pakaian apakah dalam kondisi basah atau kering.
\end{abstract}

Kata kunci: Jemuran Otomatis, Sensor LDR, Sensor Hujan, Sensor Kelembaban

\begin{abstract}
The condition of weather changes in Indonesia is uncertain, so it difficult to predict clear and rainy weather. This is still a major problem for people who are drying clothes especially in the rainy weather conditions. Usually clothes is often left out traveling, with weather conditions like this make some people feel anxious because they do not have time to lift the clothesline in the rainy weather conditions. Plus the tropical climate in Indonesia which often experiences prolonged rainfall and there are some areas that have high rainfall so that makes us wary when hanging clothes outside the home. To overcome these problems the authors make an automatic clothesline prototype using LDR sensor, rain sensor, and moisture sensor using Arduino Uno. In addition to these sensors there are also additional such as fans and DC motors. From the results of testing tools that have been made tools can work well. The tool can work when the sensor will read the weather around, LDR sensor and rain sensor function to detect the weather around, while the humidity sensor serves to detect the condition of the clothes whether in wet or dry conditions.
\end{abstract}

Keywords: Automatic Clothesline, LDR Sensor, Rain Sensor, Moisture sensor

\section{PENDAHULUAN}

Pemanasan global yang terjadi akhir - akhir ini menyebabkan pergantian musim menjadi tidak stabil. Pergantian musim yang tidak stabil mengakibatkan cuaca sulit untuk diprediksi. Kondisi ini menjadi masalah utama bagi masyarakat yang sedang menjemur pakaian terutama pada saat cuaca buruk.

Biasanya jika hendak berpergian, pakaian yang basah akan dijemur didalam rumah agar tidak terkena hujan. Hal tersebut megakibatkan pakaian lembap menjadi berbau serta membutuhkan waktu yang lama agar dapat kering. Untuk menghindarinya diperlukan proses menjemur pakaian di luar ruangan agar pakaian dapat kering secara merata akibat pemanasan dari matahari. Maka dari itu diperlukan seseorang yang tinggal dirumah untuk menjaga pakaian agar tidak terkena hujan.

Hal ini mengakibatkan pengeluaran bertambah, dikarenakan membutuhkan tenaga kerja lebih. 
Melihat kondisi ini penulis mencoba membantu para masyarakat agar proses penjemuran pakaian dapat dilakukan tanpa memikirkan gangguan hujan saat kondisi siang maupun malam hari. Untuk itu diperlukan alat yang dapat bekerja secara otomatis untuk dapat memindahkan pakaian kedalam rumah apabila terjadi hujan dan kondisi lainya.

Beberapa alat yang sudah pernah dibuat hanya menggunakan sensor hujan saja. Hal tersebut masih kurang efektif karena tidak memperhatikan kelembaban, basah dan keringnya pakaian. Maka dari itu penulis mengembangkan lagi alat tersebut dengan menambahkan sensor kelembapan yang bertujuan untuk mendeteksi apakah pakaian tersebut basah atau kering. Selain itu penulis juga menambahkan perangkat lain seperti LCD untuk menampilkan kondisi pakaian, kondisi cuaca, dan menambahkan pula kipas sebagai pengering.

Dalam (Suryanto \& Atmaja, 2017) pada perencanaan catudaya merupakan persiapan awal dalam bekerjanya suatu rangkaian dimana catudaya yang di gunakan bersumber dari tegangan listrik sebesar 220 Volt AC yang di rubah ke 12 Volt DC menggunakan Trafo dengan kapasitas 1000mA dimana pada transformator terdapat dua buah kumparan primer dan skunder yang merubah tegangan dari 220 Volt Ac ke 12 Volt Dc, serta terdapat Dioda sebagai penyearah tegangan 12 volt Dc yang masuk dan akan melewati komponen elektrolit kondensator atau lebih dikenal dengan ELCO yang berfungsi sebagai filter tegangan searah dari diode.

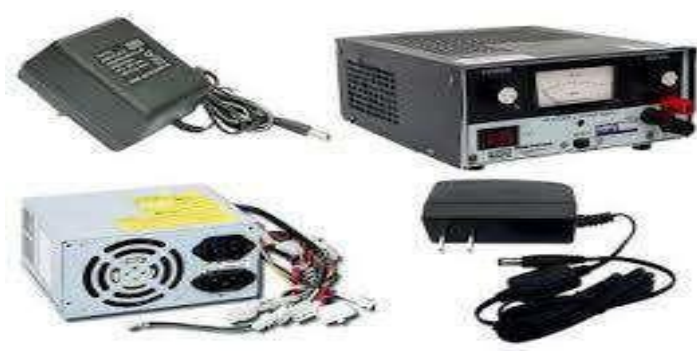

Sumber : corelita.com (2019)

\section{Gambar 1. Perangkat Catu Daya}

Beberapa perangkat keras elektronika yang digunakan untuk pembuatan prototipe ini adalah sebagai berikut.

1 Komponen elektronika pasif dan aktif yang terdiri dari komponen resistor, kapasitor, transformator dan kapasitor, dioda, transistor, dan trimmer potensio.
2 LDR (Light Dependent Resistor)

Cara kerja LDR sendiri adalah jika kondisi cahaya terang maka nilai hambatannya menjadi kecil bahkan dapat menyentuh angka nol tergantung intensitas cahaya yang mengenai LDR tersebut dan bila kondisi gelap maka hambatannya menjadi semakin besar (Suryanto \& Atmaja, 2017) .

(Hurriyatul \& Widasari, 2017) klasifikasi sinyal berdasarkan nilai data dibedakan menjadi sinyal analog dan digital, sinyal analog memiliki sinyal data dalam bentuk gelombang kontinyu, sedangkan sinyal digital memiliki sinyal data dalam bentuk pulsa dengan bilangan biner $(0$ dan 1$)$.

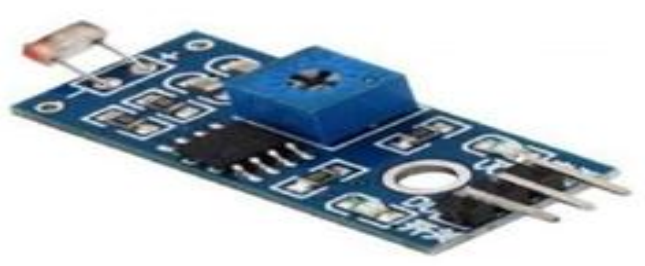

Sumber: potensiallabs.com (2019)

Gambar 2. Sensor Cahaya

3 Sensor Air Hujan

Dalam (Siswanto \& Winardi, 2015) Sensor hujan merupakan alat switching yang digerakkan berdasarkan curah air (hujan).

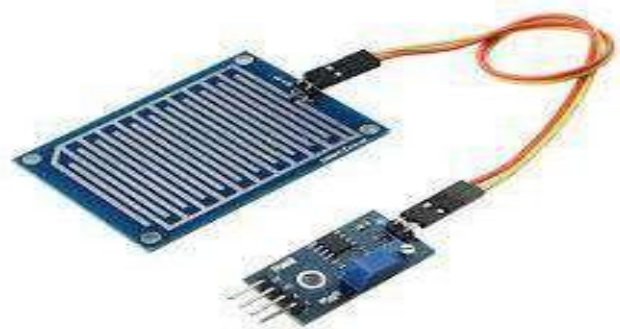

Sumber: tokopedia.com (2019)

Gambar 3. Sensor Air Hujan

4 Sensor Kelembaban

Soil mouisture sensor adalah sensor kelembapan yang memiliki spesifikasi tegangan input sebesar $3.3 \mathrm{~V}$ atau $5 \mathrm{~V}$, tegangan output sebesar $0-4.2 \mathrm{~V}$, arus sebesar $35 \mathrm{~mA}$, dan memiliki value range $\mathrm{ADC}$ sebesar 1024 bit mulai dari 0 - 1023 bit (Husdi, 2018). 


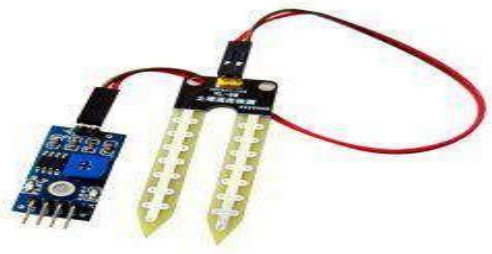

Sumbe: tokopedia.com (2019)

Gambar 4. Sensor Kelembaban

\section{Motor DC}

Motor DC merupakan motor listrik yang memerlukan suplai tegangan arus searah pada kumparan medan untuk diubah menjadi energi gerak me kanik (Ihsanto \& Rifky, 2015). Motor DC diperlukan dalam alat ini untuk menggerakkan jemuran ke dalam ruangan dan keluar ruangan

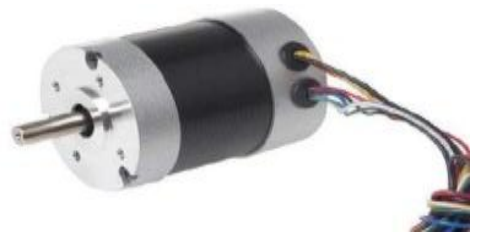

Sumber : uk.rs_online.com (2019)

Gambar 5. Motor DC

\section{Motor Driver Shield}

Motor Shield L298P dapat digunakan untuk menggerakkan dua buah motor DC 7-12V dengan maksimum arus hingga 2A. Produk ini kompetibel dengan Arduino UNO, Arduino Mega maupun board Arduino kompetibel yang lain, sehingga dapat langsung ditumpuk diatas board Arduino dengan mudah. Dengan berkembangnya dunia IC, sekarang sudah ada Motor Shield yang bisa mengoperasikan empat buah motor DC (Ihsanto \& Rifky, 2015)

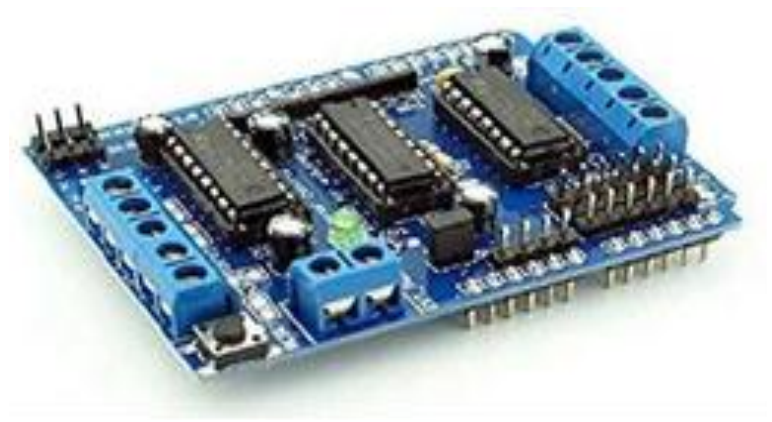

Sumber : amazon.in (2019)

Gambar 6. Motor Driver Shield
7 I2C (Inter Integrated Circuit)

I2C merupakan singkatan dari Inter Integrated Circuit, yaitu sebuah protokol untuk komunikasi serial antar IC dan sering disebut juga Two Wire Interface (TWI) (Sari, Suhery, \& Arman, 2015) Pada penelitian ini, komunikasi I2C digunakan untuk komunikasi antara mikrokontroler dan RT.

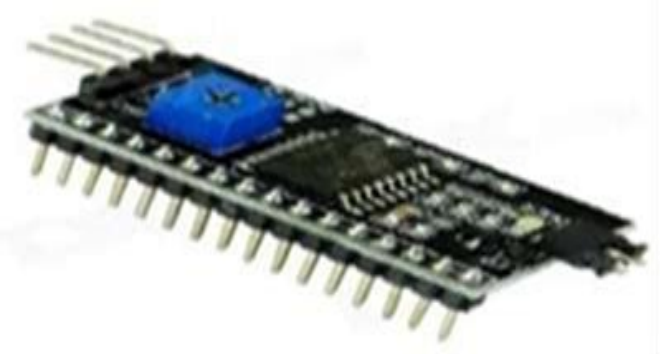

Sumber : dx.com (2019)

Gambar 7. I2C

8. LCD (Liquid Crystal Display)

LCD (Liquid Crystal Display) digunakan untuk menampilkan informasi elektronik seperti teks (huruf). angka atau symbol (Siswanto \& Winardi, 2015)

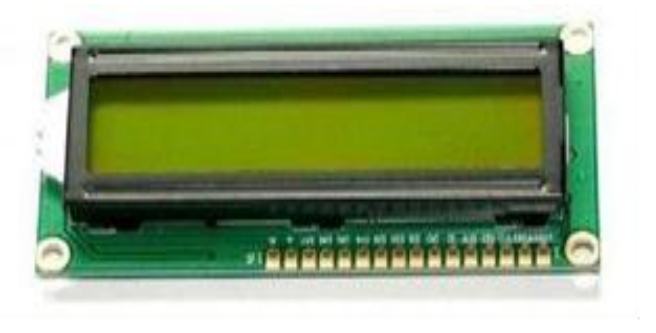

Sumber: indiamart.com (2019)

Gambar 8. LCD

Komponen utama yang berfungsi sebagai otak dari segala macam kegiatan alat ini dikendalikan oleh mikrokontroller. Mikrokontroller adalah komputer yang berukuran mikro dalam satu chip IC (integrated circuit) yang terdiri dari processor, memory, dan antarmuka yang bisa diprogram. Jadi disebut komputer mikro karena dalam IC atau chip mikrokontroller terdiri dari CPU, memory, dan I/O yang bisa kita kontrol dengan memprogramnya (Santoso, 2015). Mikrokontroller dapat diprogram menggunakan bahasa C++ (Raharjo, 2015).

Arduino merupakan platform prototyping opensource hardware yang mudah digunakan dalam membuat suatu projek berbasis pemrogaman. Arduino Board mampu membaca inputan berupa sensor, tombol dan mengolah menjadi outputan seperti mengaktifkan motor, menyalakan LED dan 
sebagainya. Anda dapat memprogam Arduino Board dengan memberikan set instruksi tertentu dengan menggunakan Arduino programming language, dan Software Arduino (IDE) (Obi, 2017). Arduino Uno dapat diaktifkan menggunakan koneksi USB (Zain \& Surmayanti, 2016)

Arduino Uno adalah papan terbaik untuk memulai dengan belajar elektronik dan coding. Papan jenis ini yang paling kuat dan yang paling banyak digunakan dari seluruh keluarga Arduino (Obi, 2017).

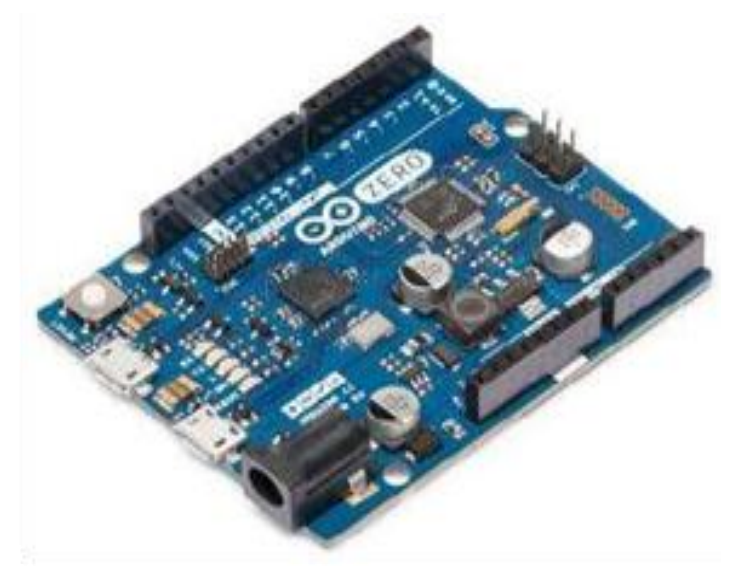

Sumber : uae.souq.com (2019)

\section{Gambar 9. Arduino UNO}

\section{METODOLOGI PENELITIAN}

Dalam penelitian ini, penulis menggunakan beberapa metode yaitu:

\section{Studi Pustaka}

Dalam rangka mencari sumber referensi yang baik, maka penulis melakukan dengan metode studi pustaka, yaitu dengan mencari informasi dari jurnal, buku dan internet yang terkait dengan penelitian.

\section{Eksperimen}

Kegitan ini digunakan oleh penulis sebagai tahap lanjut dari informasi yang telah didapatkan, yaitu dimulai dari tahap desain gambar layout, kemudian dilanjutkan dengan proses membuat alat dengan komponen yang dibutuhkan, kemudian melakukan uji coba dan troubleshooting terhadap alat yang dibuat.

\section{HASIL DAN PEMBAHASAN}

Proses utama dalam perancangan jemuran otomatis ini terdapat pada arduino UNO. Arduino UNO mengatur keseluruhan kerja rangkaian termasuk input dan output. Untuk Input kami menggunakan sensor kelembapan, sensor hujan, dan LDR. Lalu untuk output kami menggunakan motor DC, kipas, dan LCD 16x2. Pada rancangan ini Motor Driver L293D berfungsi sebagai penggerak motor DC untuk menarik atau mendorong jemuran ke dalam dan ke luar ruangan.

\section{Blok Diagram Alat}

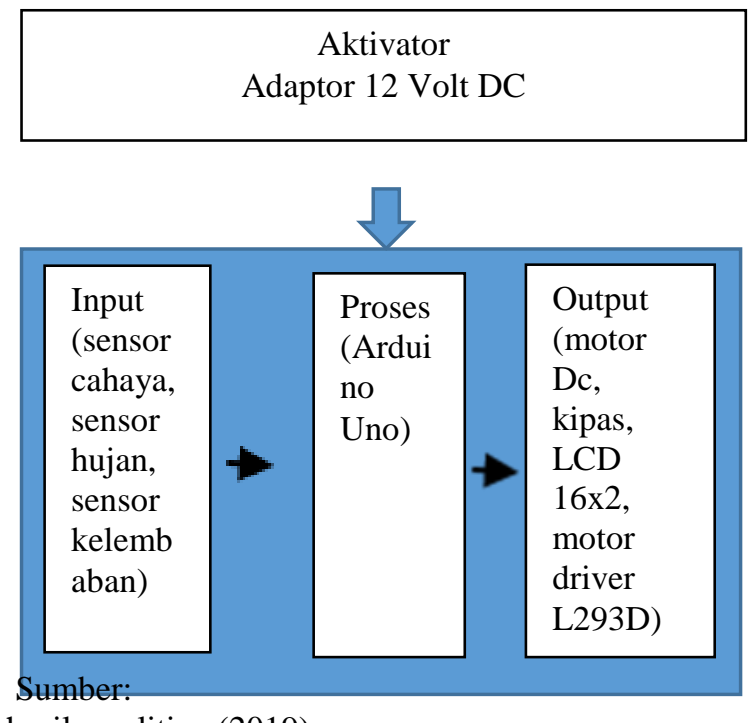

hasilpenelitian (2019)

Gambar 10. Blok Diagram Alat

Penjelasan blok diagram sebagai berikut :

\section{a. Blok Aktivator}

Aktivator merupakan bagian pada perancangan alat yang berfungsi sebagai pemberi tegangan atau catu daya untuk mengaktifkan seluruh komponen dan bagian - bagian rangkaian. Sumber tegangan untuk alat ini adalah adaptor $12 \mathrm{~V}$ untuk mengaktifkan Arduino UNO serta perangkat lainnya.

\section{b. Blok Input}

Input merupakan komponen masukan yang digunakan untuk memberi sinyal atau data kepada mikrokontroler yang akan diproses oleh komponen output.

Komponen input tersebut terdiri dari :

1) Sensor LDR (Light Dependent Resistor), berfungsi sebagai alat pendeteksi cahaya untuk mengetahui kondisi malam dan siang dengan cara memberikan sinyal analog 0 sampai 1023 dimana 0 kondisi siang 
sedangkan 1023 kondisi malam dan menampilkan kondisinya pada LCD.

2) Sensor hujan, berfungsi sebagai alat pendeteksi hujan yang memberikan sinyal digital hujan (1) dan cerah (0) untuk menggerakkan posisi jemuran ke dalam ruangan dan menampilkan kondisi cuaca pada LCD.

3) Sensor kelembaban, berfungsi sebagai alat pendeteksi kelembapan pada pakaian dengan cara memberikan sinyal analog 0 sampai 1023 dimana 0 kondisi basah sedangkan 1023 kondisi kering dan menampilkan kondisinya pada LCD.

\section{c. Blok Proses}

Di dalam blok ini Arduino Uno merupakan komponen utama yang berfungsi sebagai pengelola data yang diterima dari komponen input dan kemudian di teruskan ke komponen output.

\section{d. Blok Output}

Output merupakan hasil pengolahan sinyal/data dari komponen input yang telah diproses oleh Arduino UNO dan akan diteruskan ke komponen selanjutnya. Komponen output yang digunakan adalah:

1) Motor DC, berfungsi sebagai penggerak yang akan menggerakkan posisi jemuran ke dalam dan keluar bangunan rumah.

2) Kipas, berfungsi untuk mengeringkan pakaian ketika kondisi hujan dan kondisi malam.

3) LCD 16x2, berfungsi untuk menampilkan kondisi cuaca (hujan dan cerah), kondisi cahaya (siang dan malam), dan kondisi pakaian (basah dan kering).

4) Motor driver L293D, berfungsi sebagai h-bridge atau driver pemberi sinyal untuk menggerakan motor DC agar dapat berputar searah jarum jam atau sebaliknya dan juga dapat mengatur kecepatan putaran yang dihasilkan.

\section{Skema Rangkaian}

Berikut ini adalah skema rangkaian dari prototipe alat jemuran otomatis yang penulis rancang. Dari gambar tersebut dapat terlihat komponen-komponen elektronika yang digunakan mulai dari input sampai output.

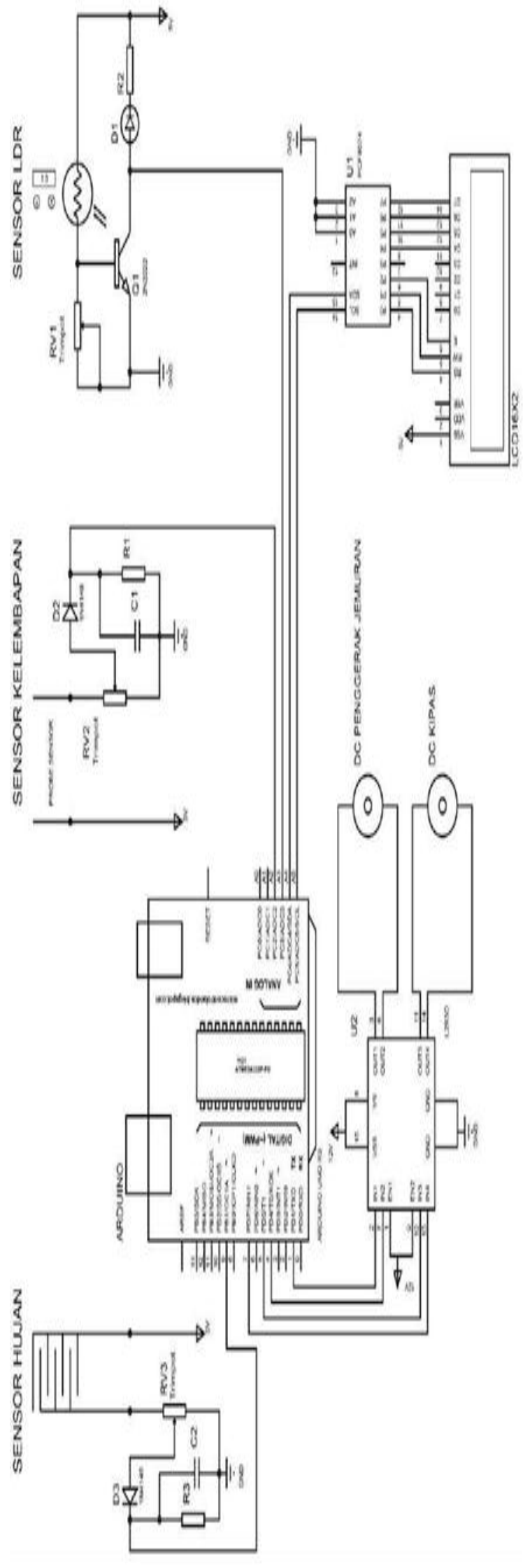

Sumber: Hasil penelitian (2019)

Gambar 11. Skema Rangkaian Alat 
Keterangan posisi pin :

Tabel 1. Posisi Pin Arduino dan Modul

\begin{tabular}{|c|c|}
\hline Modul Pin & Arduino UNO Pin \\
\hline \multicolumn{2}{|c|}{ Sensor Hujan } \\
\hline Vcc & $5 \mathrm{v}$ pin \\
\hline Gnd & Gnd pin \\
\hline DO & Pin 9 \\
\hline \multicolumn{2}{|c|}{ Sensor LDR } \\
\hline Vec & $5 \mathrm{v}$ pin \\
\hline Gnd & Gnd pin \\
\hline DO & Pin A3 \\
\hline \multicolumn{2}{|c|}{ Sensor Kelembapan } \\
\hline Vcc & $5 \mathrm{v}$ pin \\
\hline Gnd & Gnd pin \\
\hline $\mathrm{AO}$ & $\mathrm{A} 2$ \\
\hline \multicolumn{2}{|r|}{ LCD 16x2 } \\
\hline Vec & $5 \mathrm{v}$ pin \\
\hline Gnd & Gnd pin \\
\hline SCL & Pin A5 \\
\hline SDA & Pin A4 \\
\hline \multicolumn{2}{|c|}{ Motor Penggerak Jemuran } \\
\hline Positif & Input $1(\mathrm{M} 2)$ motor driver \\
\hline Negatif & Input 2(M2) motor driver \\
\hline \multicolumn{2}{|c|}{ Kipas } \\
\hline Positif & Input 1(M3) motor driver \\
\hline Negatif & Input 2(M3) motor driver \\
\hline
\end{tabular}

Sumber: Hasil penelitian (2019)

\section{Cara Kerja Rangkaian}

Rangkaian jemuran otomatis bekerja apabila cuaca memenuhi syarat kondisi yang dibuat pada listing program. Syarat utama untuk membuat alat ini bekerja adalah jika kondisi pakaian basah. Salah satu kondisinya yaitu jika cuaca cerah dan cahaya dalam kondisi terang maka dinamo penggerak pakaian akan bergerak keluar ruangan, sedangkan ketika kondisi gelap atau hujan maka jemuran akan bergerak kedalam ruangan dan kipas akan menyala untuk mengeringkan pakaian. Ketika pakaian yang ada diluar ruangan kering maka secara otomatis jemuran akan bergerak kedalam ruangan.

Arduino menggunakan 2 jenis pin yaitu pin analog dan pin digital. Pada alat ini penulis menggunakan pin analog sebagai pin pembaca nilai resistansi yang dihasilkan pada sensor LDR dan sensor kelembapan. Sedangkan pin digital digunakan sebagai pembaca nilai HIGH (5v) dan LOW (0v) atau nilai 1 dan 0 pada sensor hujan.

Sensor LDR memberikan resistansi jika cahaya terang mengenai sensor, sehingga tegangan yang masuk ke pin analog arduino akan menghasilkan voltase yang rendah. Sebaliknya jika cahaya redup atau gelap resistansi yang diakibatkan oleh sensor akan berkurang dan akan menghasilkan voltase yang tinggi.

Sensor kelembaban memberikan resistansi apabila sensor direkatkan pada pakaian yang basah karena akan membuat arus listrik merambat melalui pakaian sehingga mengakibatkan kedua panel pada probe sensor akan menyatu. Semakin basah pakaian tersebut maka semakin tinggi nilai resistasi yang dihasilkan, sebaliknya jika pakaian kering maka pakaian tidak dapat mengalirkan arus listrik sehingga resistansi yang dihasilkan rendah atau nol.

Pin digital pada jemuran otomatis digunakan untuk menentukan suatu sensor bernilai 1 atau 0 . Berikut adalah cara kerja sensor yang digunakan dalam rangkaian pin digital yaitu jika sensor hujan terkena air maka akan menghasilkan nilai 0 alasannya karna nilai positif dan negatif pada sensor terhubung akibat bercakan air sehingga akan mematikan tegangan yang masuk dari sumber tegangan. Sebaliknya jika sensor tidak terkena air atau sensor dalam kondisi kering maka akan menghasilkan nilai 1 dan arus yang masuk dalam pin akan maksimal.

\section{Flowchart Program}

Berikut ini adalah flowchart program dari alat yang telah dirancang oleh penulis. 
Jurnal Teknik Komputer AMIK BSI, Vol VI No.1 Januari 2020

P-ISSN 2442-2436, E-ISSN: 2550-0120

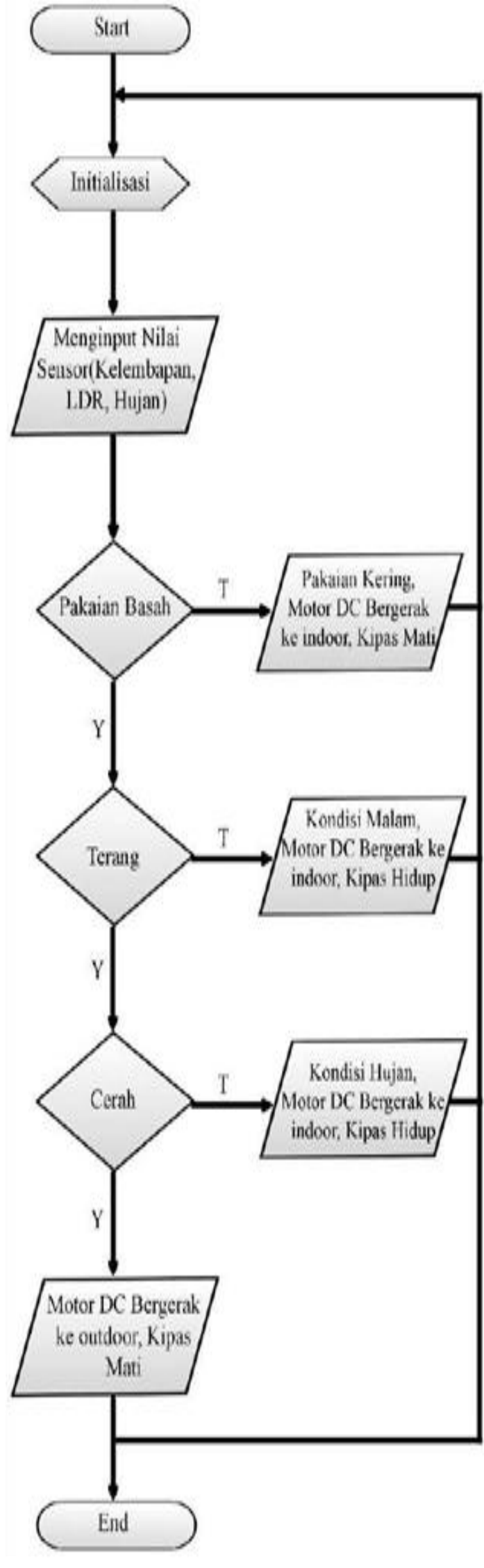

Sumber: hasil penelitian (2019)

Gambar 12. Flow Chart Program

\section{Konstruksi Sistem (Coding)}

\#include <LiquidCrystal_I2C.h>

\#include <AFMotor.h>

LiquidCrystal_I2C $1 \mathrm{~cd}(0 \times 27$,

2,1,0,4,5,6,7,3,POSITIVE); AF_DCMotor motor(2);

AF_DCMotor kipas(3);

\#define s_cahaya A3; \#define s_kelembaban A2;

\#define s_hujan 9;

int n_cahaya $=0$;

int $n \_$kelembaban $=0$; int $n \_$hujan;

int $\mathrm{j}=1, \mathrm{i}=0$;

bool indoor=true;

char* k_pakaian[]=\{"BASAH ","KERING" $\}$;

char*k_cuaca[]=\{"HUJAN","CERAH" $\}$;

char* k_ldr[]=\{"SIANG","MLM/GLP" $\}$; int x;

int $\mathrm{y}$; int $\mathrm{z}$;

void setup\{ lcd.begin(16,2);

pinMode(s_cahaya, INPUT);

pinMode(s_kelembaban, INPUT);

motor.setSpeed(80); kipas.setSpeed(180);

motor.run(RELEASE); projectBY();

\}

void loop \{ n_cahaya=analogRead(s_cahaya);

n_kelembaban=analogRead(s_kelembaban); n_hujan

= digitalRead(s_hujan);

$\mathrm{y}=\mathrm{n} \_$hujan; $1 \mathrm{ld} \_\mathrm{s}()$;

if $\left(\mathrm{n} \_\right.$kelembaban $\left.<1000\right)\{\mathrm{x}=0$;

if(n_cahaya $<400)\{$

if $\left(\mathrm{n} \_\right.$hujan $\left.==1\right)\{$ indoor $=$ false;

kipas.run(RELEASE);

\}

else \{

indoor = true; kipas.run(FORWARD);

\}

\}

else $\{$ indoor $=$ true;

kipas.run(FORWARD);

\}\}

else $\{x=1$;

indoor= true; kipas.run(RELEASE); \} notif();

delay(1000); lcd.clear();

if (indoor $==$ false $\& \& \mathrm{i}==0)\{$ notif();

motor.run(BACKWARD); delay(1000);

motor.run(RELEASE);

$\mathrm{i}=1$;

$\mathrm{j}=0$;

\}\}

if (indoor $==$ true $\& \& \mathrm{j}==0)\{$ notif $($ ); motor.run(FORWARD); delay(2000);

motor.run(RELEASE); 
$\mathrm{i}=0 ;$
$\mathrm{j}=1 ;$

\}\}

void projectBY()

\{

lcd.setCursor(0,0); lcd.print("ROBOTIC;NOTES");

lcd.setCursor $(0,1)$;

lcd.print("T.A PROJECT"); delay(4000);

lcd.clear(); lcd.setCursor(0,0);

lcd.print("VIOLETTA SURYA.P");

lcd.setCursor(0,1); lcd.print("13150361");

delay(3000); lcd.clear(); lcd.setCursor(0,0);

lcd.print("YUSUF PRIBADI.Y");

lcd.setCursor $(0,1)$;

lcd.print("13150304");

delay(3000); lcd.clear();

void ldr_s ()$\left\{\right.$ if $\left(\mathrm{n} \_\right.$cahaya $\left.>1000\right)\{\mathrm{z}=1$;

\}

else $\{\mathrm{z}=0 ;\}\}$

\section{Hasil Percobaan}

Untuk mengetahui nilai input data yang masuk maka diperlukan pengujian pada sensor-sensor yang digunakan. Pengujian sensor dilakukan untuk mengetahui apakah sensor sudah bekerja dengan baik. Pengujian yang dilakukan meliputi pengujian sensor LDR, sensor air hujan dan sensor kelembaban.

Di bawah ini adalah tabel hasil pengujian sensor pada jemuran otomatis menggunakan multitester untuk menghitung tegangan yang masuk ke arduino UNO :

Tabel 2. Pengujian Sensor LDR

\begin{tabular}{|c|c|c|}
\hline Sensor & Nilai & Keadaan \\
\hline LDR & $0.16 \mathrm{Vdc}$ & $\begin{array}{c}\text { Kondisi } \\
\text { terang }(< \\
1,96 \mathrm{Vdc})\end{array}$ \\
\hline & $4.99 \mathrm{Vdc}$ & $\begin{array}{c}\text { Kondisi } \\
\text { gelap (> } \\
1,96 \mathrm{Vdc})\end{array}$ \\
\hline
\end{tabular}

Sumber: Hasil penelitian (2019)
Tabel 3. Pengujian Sensor Kelembaban

\begin{tabular}{|c|c|c|}
\hline Sensor & Nilai & Keadaan \\
\hline Kelembaban & $3.04 \mathrm{Vdc}$ & $\begin{array}{c}\text { Pakaian } \\
\text { basah }(< \\
4,89 \mathrm{Vdc})\end{array}$ \\
\hline & & \\
& $4.98 \mathrm{Vdc}$ & $\begin{array}{c}\text { Pakaian } \\
\text { kering(> } \\
4,89 \mathrm{Vdc})\end{array}$ \\
\hline
\end{tabular}

Sumber: Hasil penelitian (2019)

Tabel 4. Pengujian Sensor Air Hujan

\begin{tabular}{|c|c|c|}
\hline Sensor & Nilai & Keadaan \\
\hline Hujan (Digital) & $0 \mathrm{Vdc}$ & $\begin{array}{c}\text { Kondisi } \\
\text { hujan }\end{array}$ \\
\hline & $5 \mathrm{Vdc}$ & $\begin{array}{c}\text { Kondisi } \\
\text { cerah }\end{array}$ \\
\hline
\end{tabular}

Sumber: Hasil penelitian (2019)

Hasil keluaran output yang digunakan dalam percobaan ini yaitu komponen perangkat keras yang mengirim hasil akhir data yang diperoleh dari sensorsensor (komponen input) dan diproses oleh arduino UNO untuk diteruskan ke perangkat selanjutnya. Komponen yang menggerakkan motor DC yaitu motor shield L293D. Pada hasil percobaan ini akan menampilkan perintah yang digunaka motor shield L293D untuk membuat motor dc bergerak pada posisi tertentu, berikut adalah data hasil percobaan:

Tabel 4. Hasil percobaan motor shield 293D

\begin{tabular}{|c|c|c|c|}
\hline \multicolumn{3}{|c|}{ Motor shield L293D } & \multirow{2}{*}{$\frac{\text { Keadaan }}{\text { Motor }}$} \\
\hline Perintah & Input 1 & Input 2 & \\
\hline RELEASE & 0 & 0 & Diam \\
\hline FORWARD & 0 & 1 & Maju \\
\hline BACWARD & 1 & 0 & Mundur \\
\hline
\end{tabular}

Sumber: Hasil penelitian (2019) 
Berikut ini adalah hasil percobaan kerja rangkaian alat secara keseluruhan.

Tabel 5. Hasil percobaan keseluruhan

\begin{tabular}{|c|c|c|c|c|c|}
\hline & \multicolumn{3}{|c|}{ Input } & \multicolumn{2}{c|}{ Output } \\
\hline $\begin{array}{c}\text { Kondi } \\
\text { si }\end{array}$ & $\begin{array}{c}\text { Sensor } \\
\text { Kelemb } \\
\text { aban }\end{array}$ & $\begin{array}{c}\text { Sensor } \\
\text { LDR }\end{array}$ & $\begin{array}{c}\text { Sensor } \\
\text { Hujan }\end{array}$ & $\begin{array}{l}\text { Posisi } \\
\text { Motor DC }\end{array}$ & $\begin{array}{c}\text { Kondisi } \\
\text { Kipas }\end{array}$ \\
\hline 1 & Basah & Terang & Kering & $\begin{array}{l}\text { Bergerak } \\
\text { ke luar }\end{array}$ & Mati \\
\hline 2 & Basah & Terang & Basah & $\begin{array}{l}\text { Bergerak } \\
\text { ke dalam }\end{array}$ & Hidup \\
\hline 3 & Basah & Gelap & Kering & $\begin{array}{l}\text { Bergerak } \\
\text { ke dalam }\end{array}$ & Hidup \\
\hline 4 & Basah & Gelap & Basah & $\begin{array}{l}\text { Bergerak } \\
\text { ke dalam }\end{array}$ & Hidup \\
\hline 5 & Kering & Terang & Kering & $\begin{array}{l}\text { Bergerak } \\
\text { ke dalam }\end{array}$ & Mati \\
\hline 6 & Kering & Terang & Basah & $\begin{array}{l}\text { Bergerak } \\
\text { ke dalam }\end{array}$ & Mati \\
\hline 7 & Kering & Gelap & Kering & $\begin{array}{l}\text { Bergerak } \\
\text { ke dalam }\end{array}$ & Mati \\
\hline 8 & Kering & Gelap & Basah & $\begin{array}{l}\text { Bergerak } \\
\text { ke dalam }\end{array}$ & Mati \\
\hline & & & & \\
\hline
\end{tabular}

Sumber: Hasil penelitian (2019)

Berdasarkan tabel tersebut, dapat disimpulkan bahwa alat ini akan bergerak keluar untuk menjemur pakaian dibawah sinar matahari jika kondisi pakaian basah, LDR menangkap kondisi terang dan sensor air hujan mendeteksi keadaan kering. Selain kondisi tersebut, alat akan bergerak kedalam.

\section{PENELITIAN LEBIH LANJUT}

a) Untuk membuat rancangan prototype agar dapat digunakan dalam kehidupan nyata, perlu menambah voltase dengan menggunakan relay yang berfungsi untuk meberi arus tegangan apabila diberi sinyal oleh arduino dan akan meneruskannya ke komponen penggerak sehingga dengan menggunakan relay inverter ( mengubah DC voltase rendah ke AC 220v) dapat mengaplikasikan motor penggerak yang bertorsi tinggi dan kipas yang bertegangan besar hingga $220 \mathrm{v}$.

b) Untuk membuat sensor probe pada sensor kelembaban dapat mendeteksi banyak pakaian, perlu mengganti sensor probe dengan ukuran yang lebih panjang sesuai dengan kebutuhan yang diperlukan sehingga dapat mendeteksi seluruh pakaian yang akan kita jemur.

c) Untuk mengatasi kurangnya sensitifitas sensor kelembapan, perlu menyetel Trimpot yang ada pada sensor hingga mencapai sensitifitas yang diinginkan . d) Untuk mengatasi kondisi sensor hujan yang basah perlu menyetel trimpot dengan mengurangi sensitifitas dari sensor sehingga sensor hanya dapat mendeteksi genangan atau percikan air yang terjadi secara terus menerus.

\section{KESIMPULAN}

Penggunaan sensor pada prototype jemuran otomatis menggunakan dua teknik pembacaan sensor yaitu secara analog dan digital. Pembacaan digital membaca nilai secara HIGH(1) dan LOW(0) dimana apabila sensor mendeteksi nilai HIGH maka voltase yang dihasilkan sensor sebesar $5 \mathrm{v}$ sedangkan nilai LOW voltase yang dihasilkan sensor sebesar 0v. Pembacaan analog membaca nilai dengan mengkonversi voltase yang dihasilkan sensor menjadi nilai ADC (Analog Digital Converter) dengan maksimal resolusi data dengan nilai 1023 yang artinya tegangan Vin yang diperoleh sensor antara rentang $0-5 \mathrm{~V}$ dikonversi ADC menjadi 01023. Dinamo jemuran begerak ke luar apabila sensor mendeteksi kondisi cerah, siang, dan pakaian dalam kondisi basah, selain dari kondisi tersebut maka jemuran akan bergerak ke dalam. Kipas akan menyala apabila kondisi pakaian basah, cuaca hujan atau pada kondisi malam/gelap, dan akan mati apabila pakaian sudah kering. Secara keseluruhan alat prototipe ini dapat bekerja dengan baik.

\section{REFERENSI}

Hurriyatul, F., \& Widasari, E. R. (2017). Dasardasar Komputasi Sinyal Didital dan Contoh Aplikasinya Menggunakan Matlab.

Husdi. (2018). MONITORING KELEMBABAN TANAH PERTANIAN MENGGUNAKAN SOIL MOISTURE SENSOR FC- 28 DAN ARDUINO UNO, 10, 237-243.

Ihsanto, E., \& Rifky, muhammad faitul. (2015). Rancang bangun Kendali Gorden dengan Saklar lampu otomatis berbasis Arduino dan. Jurnal Teknologi Elektro, 6(1), 28-37.

Obi, Z. (2017). Basic Arduino \#1. Yogyakarta: indobot robotic center.

Raharjo, B. (2015). Mudah dan Cepat Menjadi Master $\mathrm{C}++$. Informatika.

Santoso, H. (2015). Panduan Praktis Arduino untuk Pemula. Trenggalek: www. elangsakti.com.

Sari, K., Suhery, C., \& Arman, Y. (2015). IMPLEMENTASI SISTEM PAKAN IKAN MENGGUNAKAN BUZZER DAN APLIKASI ANTARMUKA BERBASIS MIKROKONTROLLER. Jurnal Coding Sistem Komputer Untan, 03(2), 111-122. Retrieved from http://jurnal.untan.ac.id/index.php/jcskommipa/ article/view/10803/10327

Siswanto, D., \& Winardi, S. (2015). JEMURAN PAKAIAN OTOMATIS MENGGUNAKAN 
Jurnal Teknik Komputer AMIK BSI, Vol VI No.1 Januari 2020

P-ISSN 2442-2436, E-ISSN: 2550-0120

SENSOR HUJAN. NARODROID, 1(2).

Retrieved from

/jurnal.narotama.ac.id/index.php/narodroid/arti cle/view/69/59

Suryanto, \& Atmaja, R. S. E. (2017). ATAP OTOMATIS TANAMAN HIDROPONIK BERBASIS MIKROKONTROLER ATMEGA 89s52, 3(1), 95-104.

Zain, R. H., \& Surmayanti. (2016). VOL . 9 NO . 1 April 2016. Jurnal Teknologi Informasi \& Pendidikan, 9(1), 67-72. 